\title{
Time and Order
}

\author{
Erwin Tegtmeier \\ Universität Mannheim \\ Department of Philosophy \\ Mannheim, Baden-Württemberg \\ Germany \\ tegtmeier@metaphysica.de
}

Article info

CDD: 115

Received: 13.11.2016; Accepted: 17.11.2016

DOI: http://dx.doi.org/10.1590/0100-6045.2016.V39N4.ET

Keywords:

Ontology

Time

Order

\begin{abstract}
An ontological analysis of time and of serial order is offered within the framework of a comprehensive ontology wherein the category of facts plays a crucial role. It is applied to distinguish them while various ways and contexts in which both have been mixed up in past and in present philosophy are discussed. The good reasons for that mix-up and the astonishing difficulty of keeping them apart are considered. The focus is more on the ontology of order than on the ontology of time. The latter is too wide a subject. It turns out that order has not really been grounded even in set theory. The ontology of serial order expounded is new. It is also needed for the adequate ontological analysis of relational facts.
\end{abstract}

\section{Ontological Theory}

In science any issue is best discussed within the context of a theory. The issue here is ontological. Hence it should be discussed with an ontological theory. Each scientific theory consists of a classification and lawful connections between the different classes. There is always leeway in applying the classification and the connections to phenomena, i.e., the same

Manuscrito - Rev. Int. Fil. Campinas, v. 39, n. 4, pp. 157-168, out.-dez. 2016. 
phenomena can be analysed by some theory differently. The classifications of ontological theories are specifically called categorisations. An ontological theory is in the first place a system of categories. My categories are particulars, universals, facts and forms. They are similar to Russell's logical atomism of $1917^{1}$. However, universals do not build a Russellian type hierarchy. The paradoxes are dealt with in another way. Therefore the same universal can be exemplified by particulars as well as by universals and by facts, that is, by entities of different categories or subcategories. For example, natural (whole positive cardinal) numbers which are relational universals hold of entities of all three categories. The example is pertinent here because of the contrast between cardinal and ordinal numbers, customarily represented by the same symbols, and because ordinal numbers play an important role in our issue. They will be categorised later.

In my ontology, as in Russell's of 1917, facts are crucial. Therefore, I will refer to it as the f-ontology. It is a theory about the basic complexes of the world. The phenomena it is designed to explain are fundamental and ubiquitous, such as existence, diversity and sameness, qualitative equality, connectedness, having properties, standing in relations, and change, necessity and possibility and the temporal and spatial features of the world. Natural numbers and order belong certainly also to those fundamental phenomena.

Ontology does not offer causal explanations. Rather it only analyses causation in general. Like mathematics it deals with structures. However, ontology distinguishes itself from mathematics by confining herself to basic structures. Moreover, the structures investigated by ontology have to exist while mathematics studies also structures which are mere possibilities. Ontology is an empirical science which has to analyse phenomena given to us in perception. As such it is in company with many other sciences with which it has to coordinate and from which is has to learn and to adopt pieces of knowledge. Naturally, the other empirical sciences can learn from ontology. For example, what physicists discuss as the problem of direction

${ }^{1}$ Cf. Russell 1956, Tegtmeier 1992, and Tegtmeier 2010

Manuscrito - Rev. Int. Fil. Campinas, v. 39, n. 4, pp. 157-168, out.-dez. 2016. 
of time is not the fundamental problem which is ontological but the more specific problem of irreversible cosmic processes. $^{2}$

\section{Serial Order}

I mean by "order" here a serial order or what in set theory is called a "strict simple order" defined by a relation which fulfils the conditions of asymmetry, transitivity and connectedness. A serial order is also called a series. What is a series in terms of the f-ontology? The dominant set theoretic view of a series which derives it from a two-term relation suggests to analyse it ontologically as a conjunctive fact, more precisely, as a conjunction of relational facts with two-term relational universals. Those relational facts contain the same two-term relation. For example, the conjunctive fact that $3 \mathrm{~cm}$ shorter than $4 \mathrm{~cm}$ and that $4 \mathrm{~cm}$ is shorter than 5 $\mathrm{cm}$ and that $3 \mathrm{~cm}$ is shorter than $5 \mathrm{~cm}$ is transitive and connected as far as the three lengths are concerned. It is not as obvious whether asymmetry holds since it involves negation. Does it hold because certain inverse facts are not in the conjunction? The f-ontology can give a definite answer because it admits negative facts. Hence the conjunctive fact must involve in addition the negative facts that $4 \mathrm{~cm}$ is not shorter than $3 \mathrm{~cm}$ and that $5 \mathrm{~cm}$ is not shorter than $3 \mathrm{~cm}$ and that $5 \mathrm{~cm}$ is not shorter than $4 \mathrm{~cm}$ to fulfil the conditions for a series.

We all have a clear concept of a series: it is ordered from the first, to the second, to the third member etc., depending on how long the series is. Obviously, a series hinges on ordinal numbers. Each member of a series has an ordinal number and all the ordinal numbers together bring those members into a series. The ordinal numbers attached are connected with a certain relation. One also says that the ordering is in a certain respect. The respect is captured somehow by the relation. However, the conjunctive fact does not seem to furnish the attachment of ordinals. Ordinals do not occur in the analysis given. It is thus not complete. The attachment of ordinals to the relata of relational facts has not yet been taken into account. However,

${ }^{2}$ See Tegtmeier 1996

Manuscrito - Rev. Int. Fil. Campinas, v. 39, n. 4, pp. 157-168, out.-dez. 2016. 
the ordinals in the relational facts of which the conjunction offered first as the ontological analysis of our series of lengths obviously cannot do the job because they are confined to the ordinals 1. (the first) and 2. (the second) since the relation in the conjuncts is only a two-term relation while our series has three members which is why the ordinal 3. (the third) is also required. But the ordinal 3. appears only in the ontological analysis with the f-ontology if there is a relational fact with a three-term relation. What is needed is therefore a three-term relation, more particularly a three-term relation with respect to length. In the fact-ontology that relation has to be a constituent of a fact. An atomic relational fact with a three-term relation would suffice for our case of the three lengths.

\section{Ordinals as Forms}

Ordinals are forms. They belong to the form of the world not to its content in contrast to positive whole cardinals which are relational universals, as was mentioned already. The cardinal 3, for example is the relational universal ' $\mathrm{x}$ and $\mathrm{y}$ and $\mathrm{z}$ count together 3". Three particulars, universals, or facts suffice to amend the relational universal 3 and to get a fact which obtains. Note that the numeral 3 in the designation of the relational universal merely specifies the cardinal but does not represent it. Only the whole expression represents it.

The contribution of an ordinal to a fact is comparatively small. Moreover, ordinals are versatile. The same relatum of a relational fact can have more than one ordinal if it occurs more than once. The two different ordinals attached to the same entity make for two different constituents of the respective relational fact. I assume that a thing or fact which is a relatum of relational facts needs to have an ordinal. But having an ordinal is not itself a fact. It merely helps to structure a relational fact. Moreover, the attachment of an ordinal to a relatum cannot be separated from the respective fact. Something is the first or the second relatum, for example, in that fact and may have another ordinal and thus another position in another fact. It does not have an ordinal outside and independently of this fact and of any fact. We have here a feature which is common to all forms. Forms are like literal forms (i.e., shapes). They are not parts of the formed things or

Manuscrito - Rev. Int. Fil. Campinas, v. 39, n. 4, pp. 157-168, out.-dez. 2016. 
facts. The ordinal attached to a thing or to a fact is not a constituent of the thing or fact respectively. I have used the term "attach" to indicate a closer connection than that created by facts between their constituents.

That the relata in a relational fact need to have ordinals is shown by the problem of difference between inverse relational facts: the two relational facts that $\mathrm{b}$ is shorter than $\mathrm{c}$ and that $\mathrm{c}$ is shorter than $\mathrm{b}$ have beforehand the same constituents according to the f-ontology, namely the two particulars b and c and the universal 'shorter'. There are good reasons to adopt the principle that two diverse facts must have diverse ontological analyses. The principle might even be considered to be a truism. However, it leads to a difficulty for our two shorter-facts. Without the ordinal we would have the same analysis on both sides although it is obvious that both sides are diverse. With attached ordinals they have different analyses. The first has $\mathrm{b}$ with the ordinal first, the second in contrast $\mathrm{b}$ with the ordinal second as a constituent.

The problem of order which arises because inverse facts have the same constituents without the acceptance of ordinals is a problem of fact ontologies with relational universals, i.e. in which relations are categorised as polyadic universals. ${ }^{3}$ Traditionally, two other views of relations were dominant: the first view which can be attributed to Plato is that relations are pairs of correlates such as (small:big) to ground the relation 'smaller' or (cause:effect) to ground the relation 'causes'; the second view (attributable to Aristotle) argues that with all those correlates only one is a property and the other side serves only to determine the property such as in 'son of Solon' or in 'effect of burning'. Both these views don't have a difficulty of distinguishing between ' $\mathrm{b}$ is shorter than $\mathrm{c}$ ' and ' $c$ is shorter than $b$ '. According to the Platonic view, in the first case $b$ is long and in the second c. According to the Aristotelian view, in the first case b is long with respect to $c$ and in the second case $c$ is long with respect to $b$.

The difficulty with inverse relational facts in a Russellian ontology is solved, as was argued, by assuming ordinal numbers and its advantage is that series which are ubiquitous and crucial in empirical sciences and mathematics can be ontologically grounded. That advantage is lacking with

${ }^{3}$ cf. Russell 1984, Bergmann 1981 and Tegtmeier 2004.

Manuscrito - Rev. Int. Fil. Campinas, v. 39, n. 4, pp. 157- 168, out.-dez. 2016. 
the two traditional views of relations, not only because those views countenance only two-term relations, but also because they do not allow for concatenations such as Plato is taller than Socrates and Socrates is taller than Simmias. In the Platonic view those are contradictory and the Aristotelian view excludes them because it takes relations to be monadic (in the sense of logic, thus not polyadic).

\section{Ordering Relations}

In the f-ontology ordinals are attached to the relata in relational facts. 'Evidently, with two-term relational facts you will have only the first two ordinals attached to the terms. Hence by those ordinals a shorter-series for our three lengths cannot be attained. Yet this shorter-series is clearly the series we mean in the case of our three centimetre-lengths. Therefore, we need a relational universal with more than two relata. We need a relational universal with exactly three relata. If we analyse a series of 30 members we need a 30-term relation. Obviously, it is difficult for us to grasp a 30member series and the respective relation. Therefore, is has become customary to break it down into two-member series involving a two-term relation. Sometimes, a three-term relation 'between' is used to make a long series cognitively accessible. That we ultimately arrive at an ordering of all the members of the series is usually overlooked or it is taken for granted that we can without actually performing the ordering. To make the order explicit a rather cumbersome relation and relational fact is required. I am implying a distinction between a series and its order. In the f-ontology that order can be identified with that big relational fact. It contains the ordinals up to nth if the series has $\mathrm{n}$ members. What about the cumbersome relation of the order fact? In our example that relation could be expressed by " $x$ is shorter than $y$ is shorter than $z$ is shorter than w" and may be symbolised by "shorter3". In this case one could dispense with the conjunctive fact and keep only the atomic relational fact with the 'relation shorter3' since we can grasp series of only four members in one fell swoop.

Manuscrito - Rev. Int. Fil. Campinas, v. 39, n. 4, pp. 157-168, out.-dez. 2016. 


\section{The Grasping the Shorter-Series}

The analysis of our shorter-series by a conjunction of two-term relational facts mirrors our cognition of such series. We proceed step by step when we grasp mentally a shorter-series. We run through it beginning with the first member and ending with the last. Strictly speaking, the conjunction contains more than the running through a series which does not involve negatives and the leap over each of the following members.

The paradigm serial order is the series of natural numbers. It is usually not analysed in set theory in terms of the relation "greater than" but in terms of the relation 'next' or 'successor of which do not allow a leap to remoter members. This analysis presents a kind of flow and assimilates seriality to time in accordance with the way we apprehend and have to apprehend longer series, including the series of natural numbers. Moreover, the counting of things proceeds in a similar way.

Those cognitive limitations and compensative methods by making a detour via time have induced Kant to claim that arithmetic is about time as geometry is about space. They inspired also the so-called operative views of arithmetic held, for example, by the Early Wittgenstein and by Paul Lorenzen. I want to argue that serial order in general and temporal serial order are distinct and that to fuse all serial order to time is a mistake.

In my ontological analysis of series in general there is no constituent which belongs to time. I analyse time in the f-ontology as two groups of relational universals. Both form a group by being mutually exclusive and jointly exhaustive. The first group consists of the relations 'earlier than', 'simultaneous with', and "overlaps temporally" and the second of the relations 'lasts longer than' and 'last as long as'. None of those relations is a constituent of series except for temporal series such as succession of chimes. The steps of counting a number of things form obviously a temporal series. However, this does not imply that the number of those things is temporal, nor that the serial order of the counting numbers is temporal.

Manuscrito - Rev. Int. Fil. Campinas, v. 39, n. 4, pp. 157- 168, out.-dez. 2016. 


\section{Misunderstanding Time}

Time is essentially passage. The temporality of grasping a shorter-series consists in proceeding from one member of it to the next. My point in the preceding paragraph was that only temporal series are passages and the most series are not although our way of grasping a longer series misleads us to think so. That thinking is usually rather indistinct but it produces not only a misunderstanding of serial order but also of time.

D. C. Williams, for example, writes in his famous paper "The Myth of Passage" this concluding statement: "Time "flows" only in the sense in which a line flows or a landscape "recedes into the west." That is, it is an ordered extension." 4 Thus Williams claims that if passage or flow is anything at all, it is serial order. The title of the paper suggests that it is nothing. The cited statement also implies that the phenomenon of passage Williams admits is not specific to time since all "ordered extensions", that is, all serial orders show it. It implies particularly that a temporal series with a time relation such as 'earlier than' would not exhibit a specific temporal passage.

Strangely enough, a philosopher which is very influential in the philosophy of time but is usually classified as having an opposite position of Williams agrees: I mean McTaggart. He insists that a series with a time relation 'earlier than' or 'later than' is nevertheless not temporal and does not exhibit passage. Williams and McTaggart differ in the bases of their analyses. Williams uses set theory and topology, McTaggart predicate logic. More precisely, McTaggart refers to Russell's analysis by an ontology which makes use of the symbols of predicate logic and claims that an analysis with relational facts cannot capture passage. The wrong fusion of serial order and time, of serial order and temporal passage leads in Williams to the reduction of temporal passage to serial order in general and in McTaggart to the denial that temporal serial order can be passage.

McTaggart's argument against the ontological analysis of temporal passage by relational facts is that relational facts do not change while the earmark of time is change. The argument rests on two category mistakes. Firstly, relational facts are used by Russell to analyse change. Therefore, it does not make sense to allow for changing facts and that fact-change does

${ }^{4}$ Williams 1966, p. 295

Manuscrito - Rev. Int. Fil. Campinas, v. 39, n. 4, pp. 157-168, out.-dez. 2016. 
not make sense is very different from the eternality of facts. Secondly, time is the basis of and thus must not change itself. Time itself is the only respect in which no change is possible. ${ }^{5}$

\section{Time as Order Again}

Kant takes time as well as space as orderings imposed upon chaotic sensory material to make further mental processing possible. Thus he conceives of time as a contribution of mind, as a mere appearance. McTaggart who is most influential in the contemporary analytical philosophy of time agrees that time in the usual sense of temporal passage is not real but he subscribes to Hegel's view that time has a ground in reality. McTaggart calls this ground of time "C-series". As is well-known, he distinguishes an $\mathrm{A}$-series of tenses and $\mathrm{B}$-series which arises from the tenses moving across a C-series. Now the suchness of the tenses and of the Aseries as well as of the relations which generate the B-series are clear. The Bseries is generated by the later- or by the earlier-relation. But on the suchness of the $\mathrm{C}$-series and of the relations generating it nothing seems to be known according to McTaggart or rather, there is nothing more to be known. The $\mathrm{C}$-series is a $\mathrm{C}$-series and nothing else and the relations generating it might be described as pure order relations such as 'follows' and 'precedes'. McTaggart retains the Kantian view that time and space are just two kinds of order where time is serial while space is a different kind of order. Thus we find here again the explicit identification of time and serial order which is nowadays made mostly implicit. I think that it is also implicit in the inductive definition of natural numbers which I mentioned already and in the definition of the series of natural numbers by the successor function. In that definition the same function is applied again and thus the series is built up through what is essentially a temporal process. This does not fit into to the general theory of series of set theory since the successor function is not a transitive relation. However, with the successor function

${ }^{5}$ s. Tegtmeier 2012

Manuscrito - Rev. Int. Fil. Campinas, v. 39, n. 4, pp. 157- 168, out.-dez. 2016. 
the nature of the order is clear: it is temporal while in the general theory of series that nature is evasive. It is said to be generated by relations but in set theory relations do not deliver order. Rather, order is presupposed and based on Cartesian products which furnish ordered pairs and greater ntuples $^{6}$ Still the n-tuples are not set theoretic entities and when they are fitted into set theory (by Lesniewski or von Neumann) the order disappears in favour of mere difference.

To explicate order in terms of ordinals, as I do, is not possible for set theory because of the definition of ordinals in this theory. All the different definitions of ordinals in logic and set theory use the concept of wellordering and set $\mathrm{X}$ is a well-ordering if and only if each non-empty subclass of $\mathrm{X}$ has a unique first element. The order used with the term "first element" is meant to be just the order of natural number expressed by "next" or "succeeding". ${ }^{7}$

Moreover, the well-orders set theorists have in mind are only what Stevens called a "nominal scales". Ordinals serve only as proper names and they represent only diversity between the named entities. They do not furnish an order, i.e. at least not an ordinal scale, with respect to dimension such as length or age. One can make a strong point that the problem of order, of serial orders has not been solved in logic and set theory ${ }^{8}$ and that therefore one tends to fall implicitly back on confusing order with time, or rather reducing all order to temporal order.

The question could be asked whether my own view of ordinals is not also implicitly temporal since it involves relations whose designations involve "coming before". My answer would be that in contrast to wellorders neither the ordinals nor the order relation are constructive or operative. They are thus not essentially the products of an iterative process of construction. Rather they are categorially determined. Ordinals belong, as

${ }^{6}$ Tegtmeier 1990

7 cf. Eisenberg 1971, $\$ 18$ (NB axiomatisation) and Shoenfield 1967, \$9.3 (ZF axiomatisation)

${ }^{8}$ cf. Tegtmeier 1995

Manuscrito - Rev. Int. Fil. Campinas, v. 39, n. 4, pp. 157- 168, out.-dez. 2016. 
was mentioned already, to the category of forms and order relations to that of relational universals. Both are connected in facts. Things with their ordinals need to be constituents of facts. Therefore, order relations are required in addition to ordinals so as to have ordering facts which connect things with ordinals. Although hence ordinals and order relations depend on facts they are taken to be existents like the facts and like other constituents of facts. What is based in set theory on constructions has to be grounded in a fact ontology on facts. The ordering fact which is an atomic fact grounds the order positions on the ordinals attached to the ordered things and the respect of the ordering (which is a property kind such as length) on the ordering relation such as being shorter 3 .

Let us look again at our example series and the corresponding ordering fact: the shorter-series is: $s(4,3) \& s(5,4) \& s(5,3)$. This conjunctive fact could also be called "reconstructive fact" with regard to longer series where we cannot grasp the corresponding ordering fact immediately. The corresponding ordering fact would be shorter $3(3,4,5)$. Making explicit the ordinals involved in the two corresponding facts would result in this formula: $\mathrm{s}(1.3,2.4) \& \mathrm{~s}(1.3,2.4) \& \mathrm{~s}(1.3,2.5)$, where the numbers with points represent ordinals. That was the reconstructive fact. The ordering fact's representation would look thus: shorter3 $(1.3,2.4,3.5)$. You see that the ordinals of the reconstructive fact do not indicate the order positions of the lengths in the series, but the ordinals in the order fact do. I referred to the two facts as corresponding facts. To explain the correspondence I would claim that the two corresponding facts are equivalent, that is to say, that if and only if one obtains then other obtains, too. Let me add, that I think it is not a case of logical equivalence.

Note, that the determining relation in the atomic relational fact, in the ordering fact is not a general ordering relation but rather a specific lengthrelation. The ordering relation indicates the respect in which the relata are ordered. In this case it is length which is a property kind to which all the different lengths belong. It is the task of the ordinals attached to the relata in the ordering fact to ground the order positions of the relata in the whole series. Anyhow, order is in any case order in some respect and the respect is mostly a property kind. The exception are time and space which are not property kinds but groups of relations. What is temporally or spatially

Manuscrito - Rev. Int. Fil. Campinas, v. 39, n. 4, pp. 157- 168, out.-dez. 2016. 
ordered is not properties (universals), but particulars, according to the relational view of time and space, I advocate. ${ }^{9}$

\section{References}

Bergmann, G. Notes on Ontology, Nous 15, 1981.

EIsenberg, M. Axiomatic Theory of Sets and Classes. New York: Holt, Rinehart and Winston, 1971.

Russelt, B. The Philosophy of Logical Atomism, in: B. Russell: Logic and Knowledge. London: George Allen \& Unwin, 1956.

Theory of Knowledge. London: George Allen \& Unwin, 1984.

SHOENFIELD, J.R. Mathematical Logic. Reading Mass.: Addison-Wesley, 1967.

TegtmeieR, E. Relations and Order, in: M.Sukale (Hrsg.): Sprache, Theorie und Wirklichkeit. Frankfurt: Peter Lang, 1990.

Grundzüge einer kategorialen Ontologie. Freiburg: Alber, 1992.

Ein vernachlässigtes ontologisches Problem der Relationslogik, in: J.Brandl (Hrsg.) Metaphysik. Neue Zugänge zu alten Fragen. Sankt Augustin: Academia, 1995.

The Direction of Time: A Problem of Ontology, not of Physics, in: J.Faye (Hrsg.) Perspectives on Time. Kluwer: Dordrecht, 1996.

The Ontological Problem of Order, in: H. Hochberg / K. Mulligan (eds.) Relations and Predicates. Frankfur: Ontos, 2004.

Three Ontologies of the Iowa School: Categories and Composition, in J. Cumpa (ed.) Studies in the Ontology of Reinhardt Grossmann. Frankfurt: Ontos, 2010.

McTaggart's Error: Temporal Change. Revue Roumaine de Philosophie 56, 2012.

Williams, D.C. Principles of Empirical Realism Springfield: C.C.Thomas, 1966.

9 A previous version of the paper was read at a conference organised by the University of Milan in Gargnano in October 2015.

Manuscrito - Rev. Int. Fil. Campinas, v. 39, n. 4, pp. 157-168, out.-dez. 2016. 